\title{
Early Neuromuscular Training after Anterior Cruciate Ligament Reconstruction
}

\author{
AL-HASSAN M.M. MOHAMED, M.Sc.*; ALAA EL-DIN A. BALBA, Ph.D.**; \\ MAHA M. MOHAMMED, Ph.D.** and MOHIE EL-DIN M. FADEL, M.D.*** \\ The Department of Musculoskeletal Disorder and their Surgeries, Faculty of Physical Therapy, \\ Pharous* and Cairo** Universities and The Department of Orthopedic Surgery, Faculty of Medicine, \\ Alexandria University***, Egypt
}

\begin{abstract}
Background: Rupture of anterior cruciate ligament is one of the most common knee injuries, Anterior Cruciate Ligament Reconstruction (ACLR) remains the standard approach for athletes who aim to return to high level sporting activities, neuromuscular training is a main part of the rehabilitation program after ACLR.
\end{abstract}

Aim of the Study: This study was conducted to detect the effect of early neuromuscular training on knee propioception after ACLR.

Methods: Thirty patients of both gender after ACLR with age ranged from 20-30 years were included in the study. All patients were referred by orthopedic surgeon who was responsible for diagnosis and surgery based on clinical and radiological examination. They were randomly assigned into 2 Groups A included 15 patients who received standard ACL rehabilitation protocol and Group B included 15 patients who received standard ACL rehabilitation protocol in addition to neuromuscular training for three sessions per week for 6 weeks. The study was conducted at a private clinic in Alexandria in the duration from November 2016 to August 2017.

Methods of Evaluation: The digital inclinometer used to assess knee proprioception (joint position sense) after ACLR.

Results: Showed that both standard ACL rehabilitation protocol (Group A) and standard ACL rehabilitation protocol adding early neuromuscular training (Group B) were effective in improvement of the knee proprioception with no statistical difference between the two groups.

Conclusion: There was no significant difference in knee proprioception between standard rehabilitation protocol with or without adding early neuromuscular training, however there was clinical difference and high percent of improvement in adding adding early neuromuscular training to standard rehabilitation protocol.

Correspondence to: Dr. Al-Hassan M.M. Mohamed, The Department of Musculoskeletal Disorder and their Surgeries, Faculty of Physical Therapy, Pharous University, Egypt
Key Words: ACL reconstruction - Rehabilitation - Neuromuscular training and propioception.

\section{Introduction}

RUPTURE of the ACL is one of the most common knee ligament injuries, with an annual incidence of 35 per 100000 people [1]. More than two hundred and thousand ACL injuries occur each year in the United States, and approximately $65 \%$ of these injuries are treated with reconstructive surgery [2] .

The ACL injury is characterized by joint instability, leading to decreased activity, which can lead to poor knee-related quality of life. It is also associated with increased risk of secondary osteoarthritis of the knee [3]

Conservative (non-surgical) interventions are used as treatment for ACL injury. This usually takes the form of a progressive rehabilitation program that includes exercises aimed at improving strength and balance [3]

Anterior cruciate ligament reconstruction remains the standard approach for athletes who aim to return to high level sporting activities [4]. It is a common procedure to allow patients to return to their former active lifestyle. Rehabilitation of the reconstructed knee is critical for the successful return to risky cutting and jumping activities [5].

Lack of neuromuscular control of the lower extremity and muscle strength (force generating capacity) are 2 of the main impairments following ACL injury therefore they are a component of rehabilitation after the injury and their reestablishment has recently been recognized as one 
of the keys for restoring dynamic joint stability and functional movement patterns [6]

Neuromuscular training is used to treat neuromuscular deficits following ACLR like the restoration of limb symmetry and normal movement patterns which will not only maximize functional performance but also decrease future injury risk. There is strong evidence for the effectiveness of this type of training in modifying risky neuromuscular patterns in healthy athletes and athletes who are ACL deficient [7].

It is essential for functional recovery following ACLR and secondary prevention (re-rupture). It should start as soon as walking without crutches is possible, with gentle non-complex exercises using minimal weight and developing from static to dynamic balance training and into agility training and sport-specific exercises [8].

Abnormal neuromuscular patterns and significant physical impairments characterize the acute post injury phase [7].

Hewett et al.; [9] stated that "balance exercises on the balance board could start early in the postoperative periods. Proprioceptive exercises actually begin when the patient steps on the ground early in the post-operative period".

There is no clearly defined starting time for proprioceptive training. Regaining confidence, absence of pain and willingness to exercise are factors contributing to the start of balance training [10]

\section{Subjects and Methods}

The study design is randomized controlled trial which was conducted from November 2016 till August 2017. Patients undergoing ACL reconstruction using Bone Patellar Tendon Bone (BPTB) graft, their age ranged from 20-30 years old and both genders. The participants were selected from a private orthopedic and arthroscopic center. After inclusion in the study all patient were asked to sign an informed consent form. Patients were excluded if they had congenital musculoskeletal deformity, rheumatic disease and any traumatic knee condition (ruptures to other knee ligaments, repairable meniscal tears).

All patient were randomly assigned using closed envelop method into 2 groups: Group (A) included 15 patients received standard ACL rehabilitation protocol and Group (B) 15 patients received standard ACL rehabilitation protocol adding early neuromuscular training.
Knee proprioception (joint position sense) assessment:

All patient joint position sense was measured by active repositioning of the lower limb using the digital inclinometer Fig. (1).

The patient was asked to sit on a raised plinth with hips and knees at 90 degree flexion with the legs dangling. The patient was tested in quiet surroundings to eliminate visual and auditory stimuli. The inclinometer was attached to the lateral aspect of the lower leg.

The clinician passively extended the patient lower leg to each of the target angles of 20, 30, 40,50 , and 60 randomly The leg was held there for 5 seconds by the clinician to allow the subject to memorize the position. The patient was instructed by the clinician not to voluntarily contract their muscles. Then, the clinician slowly returned the lower leg to the start position.

After the 5 seconds interval, patient was asked to actively reproduce the test angle with their eyes closed using the same angles and hold it for about 2 seconds, patients acknowledged verbally when they believed that they had achieved the angle, and the clinician recorded the knee angle displayed on the upper block at the reproduced position.

The angle of error which is between the targeted angle and the reproduced angle by the subject is compared pre and post the treatment to measure the difference in the joint proprioception.

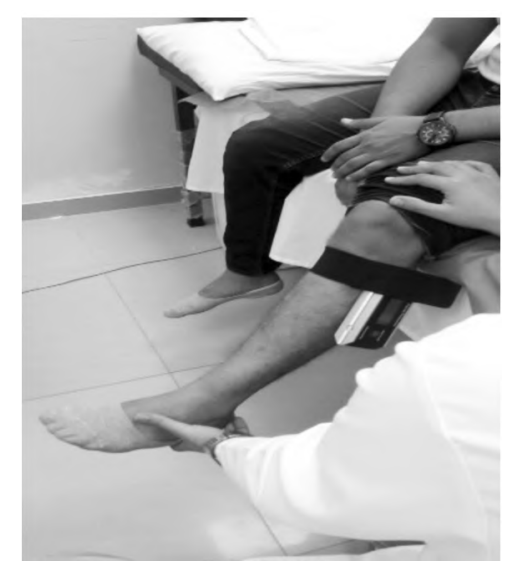

Fig. (1): Joint position sense assessment.

\section{Treatment procedure:}

Group A (control group): Fifteen patients received standard ACL rehabilitation Protocol (2, 8, and 11). Exercises in this group included patellar mobilization, gait training active knee range of motion exercises, quadriceps isometrics, hamstring isometrics, straight leg raising exercises, wall slides 
step-ups in pain-free range, incision mobilization, Prone hangs, step ups and step downs and balance exercise. Exercise was done for 3 times a week for 6 weeks duration (Appendix I).

Group B (study group): Fifteen patients received standard ACL rehabilitation protocol in addition to early neuromuscular training (Appendix II).

Post-operative Rehabilitation Program Phases (adopted from Van Grinsven et al.; [8], Adams et al., [2] and Joreitz et al., [11].

Immediate post-operative phase (week 1):

Criteria to start next phase:

1- Knee active/passive ROM $0^{\circ}$ to $90^{\circ}$.

2- Active quadriceps contraction with superior patellar glide.

Treatment:

- Patellar mobilization.

- Control of pain and inflammation through doing ice application for 10 minutes pre and post the session.

- Gait training; improve gait pattern. (Within pain tolerance).

- Neuromuscular Electrical Stimulation (NMES).

- Home exercise program: Supine wall slides, selfpatellar mobilizations $3 \times 10$ repetitions (3 times per day), quadriceps set, hamstring set and straight leg raise $3 \times 10$ repetitions ( 3 times per day).

Early post-operative phase (week 2):

Criteria to start next phase:

1 - Knee flexion greater than $110^{\circ}$.

2- Walking with or without one crutch.

3- Walking with full knee extension.

4- Reciprocal stair climbing.

5- Straight leg raise without a knee extension lag.

\section{Treatment:}

- Incision mobilization as needed (if skin is healed).

- Prone hangs.

- SLR (without extension lag). 3 sets X 10 repetitions.

- Quadriceps and gluteal sets. 3 sets X 10 repetitions.

- Hip abduction from sidelying. 3 sets X 10 repetitions.

- Patellar mobilization in flexion (if flexion is limited).
Intermediate post-operative phase (weeks 3-5):

Criteria to start next phase:

1- Knee flexion ROM to within $10^{\circ}$ of uninvolved side.

Treatment:

- Tibiofemoral mobilizations with rotation for ROM if joint mobility is limited.

- Begin balance and proprioceptive activities.

N.B.:

- The exercises in the protocol were done according to the patient tolerance.

- The patient was instructed to do the exercise at home daily as a home program.

\section{Group B:}

Patient received post-operative rehabilitation programs mentioned with Group A adding early neuromuscular training (Appendix II).

Week 1:

A- Weight shift was performed in medial and lateral direction with eye opened and tries to maintain knee in full extension as tolerated [12]

B- Ball rolling in all direction from sitting with eye opened.

C- Put his leg on step from setting.

Week 2:

A- Weight shift with eye closed in medial and lateral direction [12].

B- Weight shift with eye closed in anterior and posterior direction.

C- Forward and backward step from standing [13]

D- Sideway step [13].

E- Elastic rope in all direction [14]

F- Wall squat.

G- Standing on balance board with minimum support as tolerated [15].

Week 3:

A- Standing on balance board without support [15]

B- Star exercise [16]

C- Ball rolling in all direction from standing on sound limb with eye open and progress to eye closed.

Statistical analysis:

Descriptive statistics were used to describe subject characteristics in form of mean \pm standard 
deviation of age, weight, height and Body Mass Index (BMI) of both groups.

MANOVA test was used to test the mean difference within and between groups using SPSS for windows, Version 22 (SPSS, Inc., Chicago, IL).

\section{Results}

\section{General characteristics:}

The current study was conducted on 30 patients (10 females and 20 males) after ACL reconstruction. As indicated by the independent $\mathrm{t}$ test, there were no significant differences $(p>0.05)$ in the mean values of age, body mass, and height between both tested groups before treatment (Table 1). Chi square revealed there was no significant differences between both groups in sex distribution $(p>0.05)$.

Table (1): Physical characteristics of patients in both Groups (A \& B).

\begin{tabular}{lclc}
\hline Items & $\begin{array}{c}\text { Group A } \\
\text { Mean } \pm \text { SD }\end{array}$ & $\begin{array}{c}\text { Group B } \\
\text { Mean } \pm \text { SD }\end{array}$ & $\begin{array}{c}\text { Comparison } \\
p \text {-value }\end{array}$ \\
\hline Age (years) & $23.46 \pm 2.74$ & $22.93 \pm 2.43$ & 0.578 \\
Body mass $(\mathrm{Kg})$ & $70 \pm 8.12$ & $71.33 \pm 5.3$ & 0.599 \\
Height $(\mathrm{cm})$ & $173 \pm 7.25$ & $174.33 \pm 6.38$ & 0.597 \\
BMI $\left(\mathrm{kg} / \mathrm{m}^{2}\right)$ & $23.29 \pm 1.48$ & $23.40 \pm 1.21$ & 0.822 \\
\hline \multicolumn{5}{c}{ Group A } & Group B & $p$-value \\
\hline Female & $5(33.3 \%)$ & $5(33.3 \%)$ & 1.00 \\
Male & $10(66.7 \%)$ & $10(66.7 \%)$ & \\
*SD : Standard Deviation. & S : Significance. \\
$p \quad:$ Probability. & & NS : Non-Significant.
\end{tabular}

\section{Absolute angular error:}

\section{1- Within group's analysis:}

As presented in (Table 2) and illustrated in Fig. (2), within group's comparison the mean \pm SD values of absolute angular error in the "pre" and "post" tests were $4.15 \pm 1.34$ and $2.91 \pm 1.32$ respectively in the Group (A). Multiple pairwise comparison tests (post hoc tests) revealed that there was significant reduction of absolute angular error at post-treatment in compare to pre-treatment $(p$ value $=0.0001 *)$. While, the mean $\pm \mathrm{SD}$ values of absolute angular error in the "pre" and "post" tests were $4.56 \pm 1.80$ and $2.54 \pm 1.66$ respectively the Group (B). Multiple pairwise comparison tests (post hoc tests) revealed that there was significant reduction of absolute angular error at post-treatment in compare to pre-treatment ( $p$-value $=0.0001 *)$.

\section{2-Between groups analysis:}

Using pairwise comparison tests (post hoc tests) revealed that the mean values of the "pre" test between both groups showed no significant differences with $(p=0.487)$ and of the "post" test between both groups with $(p=0.506)$. In spite of there was no statistical significant difference between both groups, there was clinical difference and high percent of improvement in favour to Group B.

Table (2): Absolute angular error pre and post-test at both groups.

\begin{tabular}{lccccc}
\hline $\begin{array}{l}\text { Absolute } \\
\text { angular error }\end{array}$ & $\begin{array}{c}\text { Pre test } \\
\text { Mean } \pm \text { SD }\end{array}$ & $\begin{array}{c}\text { Post test } \\
\text { Mean } \pm \text { SD }\end{array}$ & MD & $\begin{array}{c}\% \text { of } \\
\text { change }\end{array}$ & $\begin{array}{c}p^{-} \\
\text {value }\end{array}$ \\
\hline Group A & $4.15 \pm 1.34$ & $2.91 \pm 1.32$ & 1.23 & $29.63 \uparrow$ & $0.0001^{*}$ \\
Group B & $4.56 \pm 1.80$ & $2.54 \pm 1.66$ & 2.01 & $44.07 \uparrow$ & $0.0001^{*}$ \\
MD & -0.41 & 0.37 & & & \\
$p$-value & 0.487 & 0.506 & & \\
$*$ * Significant level is set at alpha level $<0.05$. & \\
MD : Mean Difference. \\
$\begin{array}{l}p \text {-value : Probability value. } \\
\text { SD : Standard Deviation. }\end{array}$
\end{tabular}

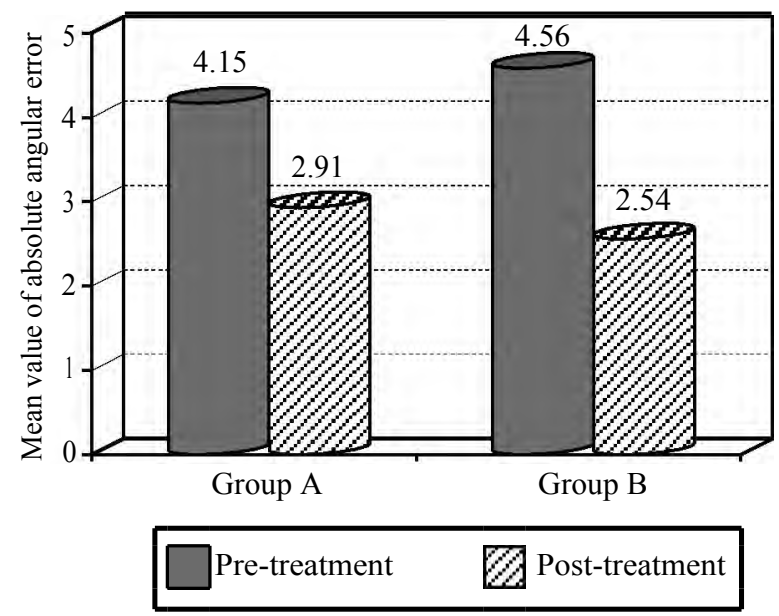

Fig. (2): Mean values of absolute angular error pre and posttests in both groups.

\section{Discussion}

Rehabilitation after ACLR is necessary for a successful surgical outcome. The main goals of rehabilitation is to control pain and inflammation and to enhance range-of-motion, strength and propioception. Neuromuscular training exercises are a part of the rehabilitation program that should be considered.

The present study was conducted on patients who underwent arthroscopic ACLR. All patients underwent standard rehabilitation protocol with or without early neuromuscular training for 6 weeks and then knee propioception was compared pre and post the treatment.

This study show a significant $(p<0.05)$ improvement in knee proprioception in both groups. These results confirmed the effective role of standard rehabilitation protocol alone or with adding early neuromuscular training on knee proprioception after ACL reconstruction. 
So our study agree with Adams et al. [2] in the importance of the standard rehabilitation protocol after ACLR in improving knee function and propioception.

Our study also agree with Holm et al. [17] whom studied the effect of neuromuscular training on proprioception and balance. The author concluded that there was a significant improvement in dynamic balance. For static balance, no statistically significant changes were found. This could be expected due to the fact that co-ordination, endurance, muscle strength and proper biomechanical movement pattern are the most problems after ACLR, which are improved by adding neuromuscular training to our rehabilitation protocol. This kind of training helpful for preventing recurrence and future injuries [21]

Our study also agreed with Paterno et al. [21] whom stated that "the balance component was improved following preseason neuromuscular training and also there were improvement of postural stability and dynamic joint stability of the knee joint".

And agreed with Akbari et al. [18] whom evaluated the effect of balance training in early stage of knee rehabilitation after ACLR and concluded that balance exercise could partially improve dynamic stability indices in early stage of ACLR rehabilitation.

This agreement might be due to the nature of the ACL as being a ligament that contains proprioceptive receptors and responsible for knee propioception so after its rupture and reconstruction knee propioception start to be affected and needs a specific type of exercises to concentrate on the propioception.

But we found in our study that there was no significant difference in knee proprioception between both groups pre and post-treatment.

In a study done by Risberg et al. [6] they measured pain and function in a randomized control trial using visual analog scale, hop tests, isokinetic muscle strength, and static and dynamic balance tests. They found that there were no significant differences between the standard group whom received traditional strength training and neuromuscular training group for the balance and proprioception. Suggesting that exercises included in the neuromuscular training program should be part of the rehabilitation program (traditional strength training without neuromuscular training) following ACLR. And the results of our study agree with them.
Our result also agree with Kruse et al. [19] whom stated that "although neuromuscular interventions are not likely to be harmful to patients, they are also not likely to yield large improvements in outcomes or help patients return to sports faster".

Founding no significant difference between the both groups is in contrary to what Akbari et al. [18] reported and this may be due to the difference in the exercise both of us used and difference in their timing in the rehabilitation protocol as he applied the neuromuscular training for 6 months after ACLR.

Neuromuscular training exercise is wide range of exercises with its progression and may be started at different time during the rehabilitation phases and that difference may be the main cause of the contradiction of the results between researchers.

\section{Conclusion:}

Based on the finding of the present study the following can be concluded:

- Both standard ACL rehabilitation protocol and standard ACL rehabilitation protocol adding early neuromuscular training are effective treatment for improve knee proprioception after ACL reconstruction.

- There was no significant difference in knee proprioception between standard rehabilitation protocol with or without adding early neuromuscular training, however there was clinical difference and higher percent of improvement in adding adding early neuromuscular training to standard rehabilitation protocol.

\section{References}

1- HENSLER D., VAN C.F., FU F.H. and IRRGANG J.J.: Anatomic anterior cruciate ligament reconstruction utilizing the double-bundle technique. Orthop. Sports Phys. Ther. J.; 42 (3): 184-95, 2012.

2- ADAMS D., DAVID L., GIORDANO A.H., AXE M.J. and MACKLER L.S.: Current Concepts for Anterior Cruciate Ligament Reconstruction: A Criterion-Based Rehabilitation Progression. Orthop. Sports Phys. Ther. J.; 42 (7): 601-14, 2012.

3- MONK A.P., DAVIES L.J., HOPEWELL S., HARRIS K., BEARD D.J. and PRICE A.J.: Surgical versus conservative interventions for treating anterior cruciate ligament injuries. Cochrane Database of Systematic Reviews; 4, 2016.

4- HEWETT T.E., DI STASI S.L. and MYER G.D.: Current concepts for injury prevention in athletes after anterior cruciate ligament reconstruction. Am. J. Sports Med.; 41: 216-24, 2013.

5- WRIGHT R.W., PRESTON E., FLEMING B.C., AMENDOLA A., ANDRISH J.T., BERGFELD J.A., DUNN 
W.R., KAEDING C., KUHN J.A., MARX R.G., McCARTY E.C., PARKER R.C., SPINDLER K.P., WOLCOTT M., WOLF B.R., and WILLIAMS G.N.: ACL Reconstruction Rehabilitation: A Systematic Review Part I. Knee Surgery J.; 21 (3): 217-24, 2008.

6- RISBERG M.A., HOLM I., MYKLEBUST G. and ENGEBRETSEN L.: Neuromuscular Training versus Strength Training During First 6 Months after Anterior Cruciate Ligament Reconstruction: A Randomized Clinical Trial. Physical Therapy; 87 (6): 737-50, 2007.

7- Di STASI S.D., MYER G.D. and HEWETT T.E.: Neuromuscular Training to Target Deficits Associated With Second Anterior Cruciate Ligament Injury J. Orthop. Sports Physio. Therpy.; 43 (11): 777-88, 2013.

8- VAN GRINSVEN S., VAN CINGEL R., HOLLA C. and VAN LOON C.: Evidence-based rehabilitation following anterior cruciate ligament reconstruction. Knee surgery, sports traumatology, Arthroscopy Official Journal of the ESSKA; 18 (8): 1128-44, 2010.

9- HEWETT T.E., Di STASI S.L. and MYER G.D.: Current concepts for injury prevention in athletes after anterior cruciate ligament reconstruction. Am. J. Sports Med.; 41: 216-24, 2013.

10- SAKA TOLGA: Principles of post-operative anterior cruciate ligament rehabilitation World J. Orthop. September 18; 5 (4): 450-9, 2014.

11- JOREITZ RICK, LYNCH ANDREW, RABUCK STEPHEN, LYNCH BRITTANY, DAVIN SARAH and IRRGANG JAMES: Patient-specific and surgery-specific factors that affect return to sport after ACL reconstruction, The International Journal of Sports Physical Therapy; 11 (2): 264-78, 2016.

12- WILK K.V. and ARRIGO C.A.: Preoperative Phase in the Rehabilitation of the Patient Undergoing Anterior Cruciate Ligament Reconstruction, Oper. Tech. Sports Med.; 24: 12-20, 2015.

13- BENNELL K.L., KYRIAKIDES M., METCALF B., EGERTON T., WRIGLEY T.V., HODGES P.W., HUNT M.A., ROOS E.M., FORBES A., AGEBERG E. and HINMAN R.S.: Neuromuscular Versus Quadriceps Strengthening Exercise in Patients With Medial Knee
Osteoarthritis and Varus Malalignment, Arthritis \& Rheumatology; 66 (4): 950-9, 2014.

14- TOPP R., WOOLLEY S., HORNYAK J., KHUDER S. and KAHALEH B.: The effect of dynamic versus isometric resistance training on pain and functioning among adults with osteoarthritis of the knee Arch. Phys. Med. Rehabil.; 83: 1187-95, 2001

15- VERHAGEN E., DER BEEK A.V., TWISK J., *LEX BOUTER L., BAHR R., and MECHELEN W.V.: The effect of a proprioceptive balance board training program for the prevention of ankle sprains a prospective controlled trial. The American Journal of Sports Medicine; 32 (6): 1385-93, 2004.

16- RISBERG M.A., MORK M., JENSSEN H.K. and HOLM I.: Design and Implementation of a neuromuscular Training Program Following Anterior Cruciate Ligament reconstruction Journal of Orthopaedic \& Sports Physical Therapy; 31 (11): 620-31, 2001.

17- HOLM I., FOSDAHL M., FRIIS A., RISBERG M., MYKLEBUST G. and STEEN H.: Effect of neuromuscular training on proprioception, balance, muscle strength, and lower limb function in female team handball players. Clinical journal of sport medicine: Official Journal of the Canadian Academy of Sport Medicine; 14 (2): 88-94, 2004.

18- AKBARI A., GHIASI F., MIR M. and HOSSEINIFAR M.: The Effects of Balance Training on Static and Dynamic Postural Stability Indices after Acute ACL Reconstruction. Global Journal of Health Science; 8 (4): 68-81, 2015.

19- KRUSE L.M., GRAY B. and WRIGHT R.W.: Rehabilitation after anterior cruciate ligament reconstruction: A systematic review. J. Bone Joint. Surg. Am.; 94 (19): 1737-48, 2012.

20- SHIM J., CHOI H. and SHIN J.: Effects of neuromuscular training on knee joint stability after anterior cruciate ligament reconstruction. Journal of Physical Therapy Science; 27 (12): 3613-20, 2015.

21- PATERNO M., MYER G., FORD K. and HEWETT T.: Neuromuscular training improves single-limb stability in young female athletes. The Journal of Orthopaedic and Sports Physical Therapy; 34 (6): 305-16, 2004. 


\section{تآثير التدريبات العصبية العضلية المبكرة العبية العيكية

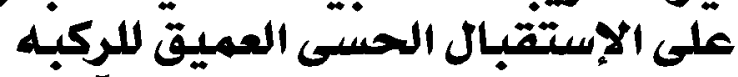

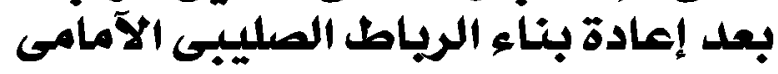

آجريت هذه الدراسة على ثالاثين مريضا بعد إعادة بناء الرياط الصليبى الآمامى اللركبه وكان متوسط العمر من عشرين إلى ثلاثين عاما

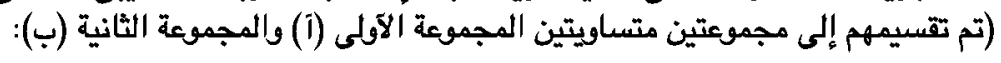

المجموعة الآولى : تككن من خمسة عشر مريضا تلقوا إعادة تآهيل بعد إعادة بناء الرباط المليبى الآمامى للركبه.

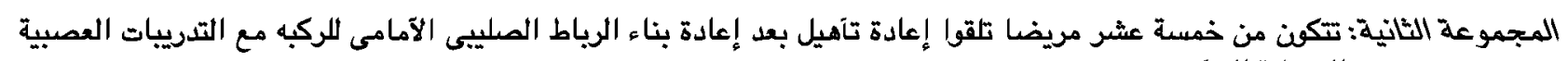
العضلية المبكرة.

طريقة القياس : تم تقيم الإستقبال الحسى العميق للركبة عن طريق إستخدام الميل الرقمى.

آظهرت النتائج وجود تحسن فى المجموعتين الآولى والثانية، وبالآخص الثانية حيث آن كان التدريبات العصبية العضلية المبكرة له عامل آساسى فى هذه النتائج. الإسبتتاج: - كلا من العلاج بتطبيق إعادة تآهيل بعد إعادة الرباط الصليبي الامامى للركبه وإعادة تآهيل بعد إعادة بناء الرباط الصليبى الآمامى للركبه هع الترريبات العصبية العضلية المبكرة يعطى نتائج كبيرة.

- لا يوجد فرق إحصائى بين تطبيق إعادة تآهيل بعد إعادة بناء الرياط الصليبى الآمامى الركبه وإعادة تآهيل بعد إعادة بناء الرباط الصليبى الآمامى للركبة هع التدريبات العصبية العضلية المبكرة. 